\title{
LER, CONTEMPLAR, INTERPRETAR OU "LIÇÃO..." VERSUS "AMAR..."
}

Terezinha Elisabeth da Silva

\section{Resumo}

Este artigo apresenta breve discussão teórica acerca das relações entre livro e filme e a respeito de adaptações cinematográficas de obras literárias. Mostra as convergências e divergências que ocorrem entre o texto de "Amar, verbo intransitivo" de Mário de Andrade e o filme "Lição de amor" de Eduardo Escorel, adaptado daquele romance.

\section{Palavras-Chave}

"Amar, Verbo Intransitivo"; "Lição de Amor"; Adaptações cinematográficas

\section{INTRODUÇÃO}

A idéia inicial deste artigo era analisar a presença do livro em filmes brasileiros, num trabalho de decupagem de obras na tentativa de verificar como as imagens selecionadas se articulariam em processos de representação. O cinema como lugar de representação e de apresentação do livro, é a proposta de minha tese de doutorado; um lugar privilegiado, mas pouco explorado como objeto de pesquisa na área da Ciência da Informação. 
Referindo-me ao livro, trato não somente do livro como objeto físico, mas do universo que orbita em torno dele, mais especificamente, das práticas de leitura, segundo conceitos e expressões propostos por Chartier (2000). Em minha pesquisa, particularmente, desdobro a idéia do autor de modo a incorporar, como objeto de estudo, não só o livro per si, mas as maneiras de ler, as formas de organização e disseminação do livro, e os modos de escrever e comercializar.

O estudo da presença do LIVRO no cinema brasileiro transformou-se, no entanto, na constatação de sua ausência, ou de uma presença incipiente em nossos filmes. Desde que a idéia do estudo fez-se clara, bancos de dados e locadoras foram consultados em busca de filmes nacionais que mencionassem pelo menos uma das categorias significativas da presença do livro. Entretanto, após contactar cinéfilos e colegas de trabalho, e depois de assistir a cerca de 30 filmes, constatei ausência quase que total daquelas categorias. As restrições de disponibilidade, conseqüência da baixa demanda por filmes nacionais e, logicamente, da fragilidade de nossa indústria cinematográfica, dificultam buscas extensivas e reduzem significativamente as possibilidades de acesso a filmes brasileiros.

Tendo voltado ao estágio inicial, optei por desenvolver um ensaio acerca do diá- logo entre uma obra literária impressa e uma obra fílmica, derivada daquela e que busca verificar como as representações do livro se articulam nessas duas obras. Assim, detenho-me no texto de Amar, verbo intransitivo, romance de Mário de Andrade, publicado em 1927, e no filme Lição de Amor (1976), dirigido por Eduardo Escorel e adaptado do romance.

\section{LITERATURA E CINEMA}

Quando uma obra literária é transposta para o cinema, é comum ouvirmos comentários do tipo: "O filme é muito diferente do livro", ou "O livro é mais completo", ou ainda, "Você precisa ler o livro para entender o filme". Não raro os jornalistas perguntam aos escritores: "Você reconhece seu livro neste filme?" Expressões como essas sugerem que há espectadores ansiosos por verem a obra literária reproduzida no texto fílmico, tal e qual apresenta-se no texto impresso. Há, portanto, a expectativa de assistir ao "livro-filme".

Embora contem histórias, filme e livro - ou a literatura e o cinema narrativo - são mídias diferentes. Não subordinadas, mas diferentes. Atuam em campos de percepção distintos, ainda que complementares, digamos, e apelam, muitas vezes, para públicos diferenciados. São elementos da indústria cultural, mas pertencem a sistemas de produção e de reprodução distintos e apresentam-se em suportes diferentes. 
Livro e filme, por se valerem de processos

e recursos diferenciados, operam experi-

ências sensoriais também distintas.

Produtos da cultura, tendem a representar o contexto social de determinada época. Materializam, através do suporte película (ou vídeo) e do suporte papel, o imaginário social. Seriam, assim, discursos que representam, apresentam e até antecipam comportamentos e desejos.

O que a literatura pode, e faz, é ampliar nossa compreensão do real, por um processo que consiste em destruílo e reconstruí-lo, atribuindo-lhe valores que, em si, ele não tem. Como toda arte "representativa", aliás. Comentando um filme sobre o garimpo, que Ihe foi mostrado, um velho garimpeiro observou: "Tudo o que está lá, a gente já conhece; mas no filme tudo transparece e a gente reconhece" (O Estado de São Paulo, 4 de maio de 1978) (PERRONE-MOYSÉS, 1990, p. 108)

Livro e filme são mídias que dialogam internamente, num processo de intertextualidade e que dialogam intensamente entre si, buscando uma "transtextualidade". Desta feita, imagem e texto, ou filme e livro, não concorrem entre si, porque não são "dois galãs competindo pela mesma bela leitora no campo de batalha intelectual." (MANGUEL, 2000, p. 282)

Ver um filme não é, por si só, um ato menos "sério", menos "cultural", ou menos "importante" que ler um livro. Há quem defenda a soberania ou a supremacia de determinada mídia ou suporte em detrimento de outros. Mas, diferença não deve signifi- car exclusão, pelo contrário, as formas de expressão podem adquirir caráter de complementaridade, sem relação de hierarquia.

O diálogo entre cinema e literatura, é a continuidade de uma relação estabelecida há muito entre a escrita e a imagem. Desde as iluminuras e miniaturas nos manuscritos medievais, mas, principalmente a partir da incorporação das tecnologias de impressão às práticas de reprodução do livro antes mesmo da Revolução Industrial - e bastante intensificadas após ela.

Diz-se que o filme é um romance com sensação cromática (SOUZA, 2000). Contudo, esta sensação do filme-romance ou do romance-filme, embora nos pareça natural, é fato muito recente. Nem sempre foi assim. Nem para o romance, tampouco para o filme. O romance, tal como o temos na contemporaneidade, é o romance moderno. Da mesma forma, o "primeiro cinema" não era um cinema que "sabia" contar histórias. Se o romance moderno era um romance desejando ser um cinema que ainda não existia, como ressalta André Bazin, o cinema parece ter nascido com o desejo de ser romance.

O êxito do teatro filmado serve ao teatro, como a adaptação do romance serve à literatura: "Hamlet" na tela só pode aumentar o público de Shakespeare, um público que pelo menos em parte gostaria de escutá-lo no palco. "Le journal d'un curé de campagne", visto por Robert Bresson, multiplicou por dez os leitores de Bernanos. Na verdade, não há concorrência e substituição, 
mas adjunção de uma dimensão nova que as artes pouco a pouco perderam desde a Renascença: a do público. (BAZIN, 1991, p. 123)

O cinema "bebe" na fonte da literatura, não só quando recorre a adaptações, mas principalmente, ao utilizar recursos narrativos da literatura. Também a literatura, em especial desde o início do século $X X$, serve-se dos recursos e do discurso cinematográfico. No Brasil, por exemplo, do final do século XIX para o início do século XX, a artesania da literatura brasileira vai se transformando em técnica, refletindo todo o esforço de modernização do país. Como observa Flora Süssekind,

Não se trata mais de investigar como a literatura representa a técnica, mas como, apropriando-se de procedimentos característicos à fotografia, ao cinema, ao cartaz, transforma-se a própria técnica literária. Transformação em sintonia com mudanças significativas nas formas de percepção e na sensibilidade dos habitantes das grandes cidades brasileiras então. Em sintonia com o império da imagem, do instante e da técnica como mediações todo-poderosas no modo de se vivenciar a paisagem urbana, o tempo e uma subjetividade sob constante ameaça de desaparição. (SÜSSEKIND, 1987, p. 15-16)

\section{AMAR, VERBO INTRANSITIVO}

\section{VERSUS LIÇÃO DE AMOR}

\subsection{Compassos...}

Lição de amor é um filme bem produzido para os padrões brasileiros da década de 1970. As imagens são cuidadas e os enquadramentos delicados. Opta pela narrativa clássica, isto é, pela seqüência natural dos acontecimentos, sem idas e vindas. Atores bem dirigidos transportam para a tela os ares burgueses da família paulistana que vive na mansão da avenida Higienópolis. A "clave de fá" de Felisberto Sousa Costa - personagem de Rogério Froes - impõe ordem na casa. A atriz Irene Ravache vive uma dona Laura abundante em carnes e panos. $E$ a chatice adolescente de Carlos é indicada pelas insistentes reclamações da irmã, Maria Luísa: "Mamãe! Olhe o Carlos!"

Telê Porto Ancona Lopez (1992), no prefácio de 1981 a Amar, verbo intransitivo, ressalta a atmosfera de cinema presente no texto de Mário de Andrade. De fato, tal atmosfera é evidente não só devido a referências múltiplas ao cinema, dadas por expressões como "beijo cinematográfico", pela passagem no cinema Royal, ou por alusões a atores americanos como Tom Mix e Bebe Daniels, mas também pela armação textual que se assemelha ao discurso cinematográfico. Exemplo disso é a narrativa ininterrupta, sem divisões de capítulos, que induz a uma leitura continuada.

Lição de amor foi o primeiro longa de ficção de Eduardo Escorel, que além de diretor, divide com Eduardo Coutinho os créditos do roteiro. Trabalho, com certeza, favorecido pelas características do texto de Amar.... No filme, alguns dos escassos 
diálogos, ou melhor, a maioria deles, são a reprodução quase fiel do texto original, a exemplo da cena inicial do filme que corresponde à primeira página do livro, ou do primeiro diálogo, no livro e no filme, entre Fräulein e Carlos.

Exceto pelas digressões do narrador, ora assumindo a voz mental de Fräulein, ora refletindo ele mesmo sobre as personagens e seu contexto social e psicológico, o texto do livro aproxima-se de um roteiro para cinema. É seco, preciso e direto. Ainda assim, ou, por isto mesmo, o autor, nas passagens destinadas a descrever lugares e situações, dá forma a uma narrativa que provoca os processos imaginativos do leitor. Formam-se imagens na tela mental do leitor. $\mathrm{E}$ ele, como que preso à cadeira do cinema, é seqüestrado pela narrativa de

\section{Amar...}

Desta feita, o leitor cria a sua Fräulein. "[...] Cada um criou Fräulein segundo sua própria fantasia [...] porém não tenho a mínima intenção de exigir dos leitores o abandono de suas Elzas e impor a minha como única de existência real." (ANDRADE, 1992, p. 57) O autor, ciente de que realiza uma obra inacabada, "libera" o leitor. Os roteiristas, da mesma forma, criaram sua Fräulein. $O$ diretor imaginou Elsa na pele de uma atriz. E Lilian Lemmertz, numa atuação precisa, dá vida à Fräulein gestada em sua própria fantasia. E, desde o lançamento do filme em 1976, para mui- tos espectadores, atriz e personagem permanecem coladas.

\section{2 ... e atropelos}

Tanto em Amar..., quanto em Lição..., o fio condutor é o idílio entre Fräulein e Carlos. No livro, porém, as personagens e situações que orbitam em torno do casal vão desenhando um mapa da vida paulistana no início do século $X X$. O filme, por sua vez, apela mais para os jogos de sedução do casal. Lição... termina quando acaba o "idílio dos dois". Neste ponto de Amar...., o autor diz que "o livro está acabado", embora o texto continue por mais dez páginas.

A São Paulo contraditória e no afã da modernidade, a transformação da massa em multidão e o relativo nervosismo de uma sociedade em mudança, são aspectos suprimidos no filme, ou apenas esboçados em diálogos. Em Lição..., imagens que mostram os contrastes da vida coletiva como o Vale do Anhangabaú, o corso da avenida Paulista e os bondes "macaqueando" pelas ruas - são elididos, privilegiando-se focalizar a vida aparentemente rotineira da "família imóvel", naquela mansão que abriga os filhos da burguesia paulistana dos perigos do mundo real. Este, um espaço que não se revela, espaço extra-diegético ou que está fora da ação das personagens. 
A única vivência da família no espaço exterior à mansão, ocorre na seqüência da viagem ao Rio, mas somente lendo o livro se sabe para onde viajam. Em Lição..., é clara a supressão de detalhes em relação ao livro, que revela, nesta passagem, a dinâmica do grupo de personagens atuando. Deste modo, o contraste evidenciado no livro, entre a vida na capital paulistana e o ambiente bucólico da floresta da Tijuca no Rio, é bastante desfocado no filme. A família, embora fora de casa, permanece fechada em si mesma.

No que diz respeito aos jogos de sedução, Amar... consegue orquestrar um clima crescente de sensualidade e erotismo que envolve o casal. (ANDRADE, 1992, p. 89-92) Em movimento, primeiramente suave, depois andante, até chegar próximo do clímax - não alcançado porque as regras ditadas pelo jogo amoroso exigem crescente grau de dificuldade antes de se revelarem as delícias do amor. Impressionante constatar que no filme Lição de Amor, a despeito da atuação da protagonista e da força da imagem cinematográfica, os deleites do casal são frios e lineares, quase que previsíveis.

\subsection{Olho e câmera (des)construindo o texto}

No livro Amar, verbo intransitivo, "O Narrador que capta a cena no que ela tem de essencial, freqüentemente nos faz lem- brar a representação cinematográfica: a câmera que segue os passos, foco isento, olhando por detrás, ou foco comprometido que faz as vezes dos olhos da personagem" (LOPEZ, 1992, p. 15)

No filme, imagens nítidas, sem esmaecimento, imprimem secura e realismo à obra. Essas imagens são resultado de grande profundidade de campo, procedimento ótico que permite a nitidez de todos os elementos que compõem as cenas e dão impressão de "naturalidade".

A imobilidade da família da Higienópolis é denunciada em Lição..., por movimentos lentos de câmera, pela profusão de planos fixos, com personagens, às vezes, imóveis como num retrato. A música é repetitiva; primorosa, mas repetitiva. Tanto a música em off, quanto os ensaios de Maria Luísa.

A rotineira hipocrisia do grupo é indicada por constantes entradas e saídas de Sousa Costa, que antes de ir ao "clube" e após descer as escadas, pára diante do espelho e escova o paletó. Da mesma forma, no retorno, detém-se frente ao espeIho, corre a escova pelo paletó eliminando os indícios das proezas extra-muros. Depois, sobe as escadas e dirige-se para o quarto.

Mas a família permanece imóvel naquela mansão cuja imponência é revelada, 
no início e no final do filme, por travellings ${ }^{1}$ laterais lentos e suaves. Esses travellings simulam o olhar de Fräulein de dentro do carro em movimento. Tanaka, o empregado japonês, encarrega-se de abrir o portão na chegada de Fräulein e de fechá-lo, quando ela vai embora, no final do filme. "Nada. Só Tanaka fechando o portão..." (ANDRADE, 1992, p. 138) Tomadas em plongées $^{2}$ acentuados sujeitam Tanaka que abre o portão: chegada e partida de Fräulein.

Freqüentes plongées e contreplongées acentuados fixam a escada da mansão e denotam a rotina da família. As personagens descem e sobem, eternamente, as escadas. Entram e saem dos espaços íntimos da casa. Imobilismo e rotina. Nessa rotina, Carlos tortura, incansavelmente, a irmã que sempre reclama: "Mamãe! Mamãe! Olhe o Carlos!"

Tomadas em close up descrevem delicadamente os pormenores de Fräulein e denunciam o olhar fixo de Carlos nos detaIhes da moça. "O que mais atrai nela são os beiços, curtos, bastante largos, sempre encarnados. [...] Olhos castanhos, pouco fundos. [...] $\bigcirc$ menino aluado como sempre. Fixava com insistência um pouco de viés... Seria a orelha dela?" (ANDRADE, 1992, p. 58) São os close ups que também

\footnotetext{
${ }^{1}$ Movimento resultante do deslocamento da câmera em trilhos ou carrinho.

2 Plongée: ângulo de tomada com a câmera acima do objeto. Contre-plongée: com a câmera abaixo do objeto.
}

desenham o contraste entre as culturas: os olhos de Tanaka, os olhos da alemã. "Elsa trouxe de novo os olhos de fora. O criado japonês botara as malas no meio do vazio." (ANDRADE, 1992, p. 50)

Próximo do final, Fräulein deve ir embora. E a vida entre as paredes amarelas da mansão assobradada, recobrará sua normalidade. Em Lição..., numa seqüência em planos médios, ${ }^{3}$ câmera fixa, a família posa para fotografias. As personagens se arranjam frente à câmara fotográfica. Recompõem-se a ordem e a disciplina na família de Felisberto:

Depois a mesma coisa recomeça, o polvo readquire o tentáculo que faltava. Com a mesma naturalidade quotidiana, pratica o destino dele: prover e vogar. Sobe à tona da vida ou desce porta adentro, na profundeza marinha. Profundeza eminentemente respeitável e secreta. Quanto à tona da vida, já se conhece bem a fotografia: A mãe está sentada com a família menorzinha no colo. O pai de pé descansa protetoramente no ombro dela a mão honrada. Em torno se arranjam os barrigudinhos. A disposição pode variar, mas o conceito continua o mesmo. Vária disposição demonstra unicamente 0 progresso que nestes tempos de agora fizeram os fotógrafos norteamericanos. (ANDRADE, 1992, p. 53)

\subsection{Livros, leitores e quejandos}

A abertura de Lição... mostra, sobre um fundo vermelho, linhas brancas que

\footnotetext{
${ }^{3}$ Plano médio: homem em pé. O plano é determinado pelo lugar da câmera com relação ao objeto filmado.
} 
sugerem um livro aberto, ou pentagrama, e que serve de apoio aos créditos do filme. Em seguida, os créditos iniciais de produção são apresentados: título, direção e roteiro. A seqüência inicial mostra o contrato entre Fräulein e Sousa Costa. E então mais uma seqüência de créditos. Depois, segue-se o idílio. E no final do filme, após a saída de Elsa, é mostrada outra seqüência de créditos sobre aquele mesmo fundo. $\mathrm{O}$ livro-filme pode ser fechado.

O diálogo de Amar... com o mundo das letras fica evidente nas inúmeras alusões a livros e autores, em citações textuais de trechos de poemas, na revelação da importância da biblioteca para Sousa Costa. Os livros também são reverenciados em Lição..., mas seus títulos não são mostrados, tampouco existe a profusão de citações e referências a autores.

Os papéis que os livros e outros suportes de leitura representam no filme, associam-se às funções que eles desempenham para as personagens.

"Fräulein é muito instruída, lê tanto!", comenta dona Laura. Enquanto a governanta devora livros, os seus e os da biblioteca da mansão, dona Laura prefere jornais.

Folheava o jornal. Os olhos dela, descendo pela coluna termométrica dos falecimentos e natalícios, vinham descansar no clima temperado do folhetim. Às vezes ela acordava um romance da biblioteca morta, mas os livros têm tantas pá- ginas... Folhetim a gente acaba sem sentir, nem cansa a vista. (ANDRADE, 1992, p. 59)

$\mathrm{Na}$ seqüência no hall da mansão, a família toda, exceto Carlos, está reunida após o jantar. Fräulein tem um livro aberto no colo. Dona Laura passeia os olhos pelo jornal. As meninas, no chão, desvendam um livro ilustrado. E Sousa Costa solta espessas baforadas.

Em Lição..., dona Laura diz: "Pra vir ao Brasil [Elsa] decorou página por página, o dicionário Michaelis". Entre orgulhosa e, talvez, enciumada, dona Laura ressalta as qualidades da educação de Fräulein; ela mesma, entretanto, permanece fiel aos folhetins.

Amar..., gradativamente, enumera as leituras de Fräulein: Göethe, Camões, Shakespeare, Heine. Leituras difíceis para dona Laura, burguesa, brasileira e preguiçosa. Leituras que demonstram o grau de erudição de Elsa e que acentuam sua superioridade em relação aos brasileiros.

A biblioteca de Sousa Costa só é despertada de seu "sono egípcio" quando Fräulein retira dela algum livro. Afora isto, é um mero elemento de composição do cenário da casa. São livros comprados a metro que simbolizam uma ilustração que Felisberto não tem pois ele lê apenas os livros que contabilizam os negócios com os bois de sua fazenda. Os livros da biblioteca são "livros virgens. Nem cortados alguns." (ANDRADE, 1992, p. 90) 
Entediado como sempre, Carlos passeia pelo filme com seus livros escolares. Mas só parece se interessar por eles quando se envolve com a professora. Como estratégia de sedução, o rapaz compra revistas alemãs e as oferece a Fräulein. Aí leitura passa a ser um instrumento que atrai. Puro encantamento.

E a biblioteca transforma-se, então, em cenário para os jogos de sedução. Escola de amor com seus livros depositados sobre a escrivaninha. Carlos está deitado no colo de Fräulein; os amantes têm os olhares cruzados, mergulhados. $\mathrm{E}$ os amantes dizem a última estrofe d' $A$ canção do exílio, alternando versos em português e alemão. Fräulein partirá em breve. Exilada e saudosa da terra natal, servirá a outra família. Mas, que terá Carlos aprendido com as lições amorosas e literárias da professora? Como herdeiro de Felisberto, sairá pela noite, escovará o terno ao sair e ao chegar. Subirá as escadas. Carlos é mais um Sousa Costa que deixará a biblioteca dormir seu sono egípcio.

\section{REFERÊNCIAS}

ANDRADE, Mário de. Amar, verbo intransitivo: idílio. 18. ed. Belo Horizonte; Rio de Janeiro: Villa Rica, 1992.

BAZIN, André. O cinema: ensaios. São Paulo: Brasiliense, 1991.

CHARTIER, Roger. A ordem dos livros: leitores, autores e bibliotecas na Europa entre os séculos XIV e XVIII. Brasília: Ed. UnB, 1994.

LIÇÃO de amor. Direção: Eduardo Escorel. Roteiro: Eduardo Escorel e Eduardo Coutinho. Intérpretes: Lilian Lemmertz, Rogério Fróes, Irene Ravache, Marcos Taquechel e outros. Música: Francis Hime. [S. I.]: Globo Video, 1976. (81 $\mathrm{min}$ ) VHS, son. color.

LOPEZ, Telê Porto Ancona. Uma difícil conjugação. In: ANDRADE, Mário de. Amar, verbo intransitivo: idílio. 18. ed. Belo Horizonte; Rio de Janeiro: Villa Rica, 1992.

MANGUEL, Alberto. No bosque do espeIho. São Paulo: Companhia das Letras, 2000.

PERRONE-MOYSÉS, Leyla. A criação do texto literário. In: Flores na escrivaninha: ensaios. São Paulo: Companhia das Letras, 1990.

SOUZA, Tania C. Clemente de. Discurso e Imagem: perspectivas de análise do não verbal. Ciberlegenda, n. 1, 1998. Disponível em: <http://www.uff.br/mestcii/rep.htm> Acesso em: 03 nov. 2000.

SÜSSEKIND, Flora. Cinematógrafo de letras: literatura, técnica e modernização no Brasil. São Paulo: Companhia das Letras, 1987.

\section{Terezinha Elisabeth da Silva}

Professora do Departamento de Ciência da Informação da Universidade Estadual de Londrina telis@uel.br 


\section{Title}

Reading, contemplating, interpreting or "Lição" versus "Amar"

\section{Abstract}

This article presents a brief theoretical approach concerning the relationship between books and films and regarding the cinematographic adaptations of literary works. It shows convergences and divergences between Mario de Andrade's novel "Amar, Verbo Intransitivo" and Eduardo Escorel's movie "Lição de Amor", which is an adaptation of that novel.

\section{Keywords}

Cinematographic adaptations

\section{Titulo}

Leer, comtemplar, interpretar o "Lição" versus

"Amar"

\section{Resúmen}

Este artículo presenta un breve debate teórico referente a la relación entre los libros y las películas y igualmente a las adaptaciones cinematográficas de obras literarias. Muestra convergencias y divergencias que ocurren entre el texto de "Amar, Verbo Intransitivo", de Mario de Andrade y "Lição de Amor", película de Eduardo Escorel, basada en la novela de Mario de Andrade.

\section{Palabras Clave}

Adaptaciones Cinematográficas 